\title{
Correction to: The Reduced Order Method for Solving the Linear Complementarity Problem with an M-Matrix
}

\author{
Xi-Ming Fang ${ }^{1} \cdot$ Heng-Jun Zhao ${ }^{2} \cdot$ Jing $\mathrm{Li}^{3} \cdot$ Zhijun Qiao $^{4}$
}

Published online: 22 February 2022

(c) The Author(s) 2022

\section{Correction to: Journal of Nonlinear Mathematical Physics https://doi.org/10.1007/s44198-022-00029-w}

In this article affiliation 3 was incorrectly assigned to Zhijun Qiao. The original article has been corrected.

Open Access This article is licensed under a Creative Commons Attribution 4.0 International License, which permits use, sharing, adaptation, distribution and reproduction in any medium or format, as long as you give appropriate credit to the original author(s) and the source, provide a link to the Creative Commons licence, and indicate if changes were made. The images or other third party material in this article are included in the article's Creative Commons licence, unless indicated otherwise in a credit line to the material. If material is not included in the article's Creative Commons licence and your intended use is not permitted by statutory regulation or exceeds the permitted use, you will need to obtain permission directly from the copyright holder. To view a copy of this licence, visit http://creativecommons.org/licen ses/by/4.0/.

The original article can be found online at https://doi.org/10.1007/s44198-022-00029-w.

\author{
Zhijun Qiao \\ zhijun.qiao@utrgv.edu \\ Xi-Ming Fang \\ fangxm504@163.com \\ Heng-Jun Zhao \\ zhhj.zhao@139.com \\ Jing Li \\ leejing@bjut.edu.cn
}

1 School of Mathematics and Statistics, Zhaoqing University, Zhaoqing 526000, People's Republic of China

2 Department of Mathematics and Finance, Key Laboratory of Graph Theories and Applications, Chongqing University of Arts and Sciences, Chongqing 400000, People's Republic of China

3 Interdisciplinary Research Institute, Faculty of Science Beijing University of Technology, Beijing 100124, People's Republic of China

4 School of Mathematical and Statistical Sciences, The University of Texas Rio Grande Valley, Edinburg, TX 78539, USA 